Article

\title{
Effect of Atmospheric Pressure Plasma Treatment on Adhesive Bonding of Carbon Fiber Reinforced Polymer
}

\author{
Chengcheng Sun ${ }^{1}$, Junying Min ${ }^{1,2}, * \mathbb{D}$, Jianping Lin ${ }^{1,2, *}$ and Hailang Wan ${ }^{1}$ \\ 1 School of Mechanical Engineering, Tongji University, Shanghai 201804, China; 15902132360@163.com (C.S.); \\ hailang_wan@tongji.edu.cn (H.W.) \\ 2 Key Lab of Vehicle Aerodynamics and Vehicle Thermal Management Systems of Shanghai, Tongji University, \\ Shanghai 201804, China \\ * Correspondence: Junying.Min@tongji.edu.cn (J.M.); jplin58@tongji.edu.cn (J.L.); \\ Tel.: +86-021-6958-9485 (J.M.); +86-021-6958-3943 (J.L.)
}

Received: 18 December 2018; Accepted: 9 January 2019; Published: 15 January 2019

\begin{abstract}
To improve the strength of the adhesive-bonded carbon fiber reinforced polymer (CFRP) joints, atmospheric pressure plasma treatment (APPT) was used to treat a CFRP substrate surface. This study investigated the effects of nozzle distance (i.e., the distance between plasma nozzle and CFRP substrate) and nozzle speed (i.e., the moving speed of plasma nozzle relative to CFRP substrate) of APPT on the lap-shear strength of adhesive-bonded CFRP joints. Results show that the lap-shear strength of plasma-treated CFRP joints increased to a peak value and then decreased as the nozzle distance increased, and the nozzle distance associated with the peaked joint strength depends on the applied nozzle speed. The lap-shear strength of plasma-treated adhesive-bonded CFRP joints reaches up to $31.6 \mathrm{MPa}$, compared to $8.6 \mathrm{MPa}$ of the as-received adhesive-bonded CFRP joints. The surface morphology of plasma-treated CFRP substrates was investigated by scanning electron microscope observation, and the mechanism associated with the improved joint strength after applying APPT was revealed through surface chemistry analysis. It is found that APPT not only effectively removed the content of $\mathrm{Si}$ element and $-\mathrm{CH}_{3}$ (i.e., the main compositions of release agent) from the as-received CFRP substrate surface, but also generated many polar groups (i.e., $-\mathrm{NH}_{2},-\mathrm{OH}$, $-\mathrm{COOH}$, etc.), which has a positive effect on increasing the wettability and interfacial bonding strength of CFRP substrates and consequently results in a significant improvement of lap-shear strength of plasma-treated CFRP joints. In addition, the result of differential scanning calorimetry (DSC) test shows that the surface temperature of CFRP substrate should not exceed $175.3{ }^{\circ} \mathrm{C}$ during APPT. In this study, an empirical model governing temperature, nozzle distance and nozzle speed was established to guide the selection of atmospheric pressure plasma treatment process parameters in industrial manufacture.
\end{abstract}

Keywords: carbon fiber reinforced polymer; atmospheric pressure plasma treatment; surface modification; shear bond strength

\section{Introduction}

Due to the high specific strength, corrosion resistance, and good formability, carbon fiber reinforced polymers (CFRP) are increasingly used, especially in automotive areas and aerospace fields [1-3]. Compared with other traditional joining techniques (e.g., riveting, welding, etc.), adhesive bonding does not damage and weaken CFRP substrates. Besides, the adhesive bonding structure not only has the merit of excellent mechanical properties, for example, high shear strength and high fatigue resistance, but also has significant cost advantages. Therefore, it has become a popular method 
in CFRP joining [4,5]. However, the bonding strength of the as-received CFRP joint is low due to the presence of the mold release agent and other contaminations on the as-received CFRP substrate surface [6]. In order to achieve a high strength adhesive bond, the surface of CFRP substrate needs to be cleaned and activated before applying the adhesive.

The surface treatments of CFRP can be classified into mechanical surface treatments (e.g., manual abrading, grit blasting, etc.) and chemical surface treatments (e.g., acid oxidation, coupling agent treatment, etc.) [7-9]. Manual abrading and grit blasting have the disadvantages of damaging carbon fibers and producing contaminations during these processes, which need to be secondly cleaned [10]. The chemical surface treatments have drawbacks such as low efficiency and environmental pollution. Compared with mechanical and chemical surface treatment, plasma surface treatment has attracted more and more attention, because of the advantages of high efficiency and environmental friendliness. Plasma treatment used to have a requirement of low pressure, which resulted in additional costs to ensure the vacuum of the plasma treatment system [11,12]. In addition, the size of the vacuum chamber limited the size and number of pretreated CFRP. With the development of plasma source using at atmospheric environment, APPT overcomes the disadvantage of low pressure plasma treatment and enables the application of this technology in industrial production [13]. Therefore, APPT has become the focus of studying in the adhesive bonding of CFRP.

Several studies [14-19] have indicated that the effective application of plasma treatment for the surface modification of polymer materials can improve adhesive bonding strength. Kim et al. $[14,15]$ applied Ar plasma treatment to CFRP surface in a vacuum for studying the influence of process parameters (e.g., voltage, time, and pressure) on the wettability and bonding strength. Their experiment results showed that when the vacuum pressure varied between 400-800 mTorr, power supply varied between 10-30 W, and the treatment time varied between 10-120 s, the plasma surface treatment achieved desired results. Williams et al. [16] used atmospheric pressure helium and oxygen plasma treatment to improve the adhesion between the epoxy composites and stainless steel. Their research showed that after plasma activation, the lap-shear strength had an increase of $80 \%$ for stainless steel coupons and $150 \%$ for carbon-fiber epoxy laminates. Furthermore, APPT had been used by Zaldivar et al. [17] to treat carbon fiber reinforced epoxy composite, which increased the wettability and carboxyl groups' concentration of substrate surface, and consequently, the bonding performance of the adhesive-bonded joints increased from 16.5 MPa to $25 \mathrm{MPa}$. Similar methods were used by Jan et al. [18] to improve the bonding strength of the polyamide 6 composites. Comyn et al. [19] found that plasma treatment could generate rich $-\mathrm{CO}-,-\mathrm{OH}$ bonds on the substrate surface, which has strong binding force with epoxy adhesive. In addition, plasma-treated CFRP surfaces has good stability, which can be stored under laboratory conditions up to 3 months without obvious loss of enhanced adhesion properties. In our previous study [20], it was found that the nozzle distance (i.e., distance between plasma nozzle and CFRP substrate) had an obvious impact on surface modification of a sheet molding compound (SMC), including remove of release agent, increase in the $\mathrm{O}$ and $\mathrm{N}$ contents and enhanced wettability. To increase surface treatment efficiency and obtain desired bonding strength of CFRP, it is necessary to study the effect of nozzle distance and nozzle speed (i.e., the moving speed of plasma nozzle relative to CFRP substrate) on the bonding performance of adhesive-bonded CFRP joints. In addition, the existence form of chemical elements on the CFRP surface requires further analysis and the effect of temperature on the bonding strength of CFRP should be well understood.

The objective of this study is to understand the effect of plasma surface treatment on the performance of adhesive-bonded CFRP joints for achieving the industrial automation application of APPT. This study mainly consists of four parts: the first part introduces experimental materials and procedures. The second part describes the experiment results about the lap-shear strength and fracture modes of the adhesive-bonded CFRP joints. The third part analyzes the effect of plasma treatment on CFRP substrate from the aspects of surface morphology, the change of surface chemical functional groups and surface wettability. In the last part, the improving mechanism of APPT on the lap shear strength of adhesive bonded CFRP joints is discussed. 


\section{Experimental Details}

\subsection{Materials}

The CFRP used in this study was consisted of E44/51 epoxy resin and T300-12k pan-based carbon fibers. The material properties of the epoxy resin and carbon fibers provided from the suppliers are listed in Tables 1 and 2, respectively. Carbon fiber prepregs were placed on a die coated with release agent (i.e., dimethyl-silicon oil) and then put in an autoclave to cure. The curing condition was $120^{\circ} \mathrm{C}$ for $2 \mathrm{~h}$ with a pressure of $0.69 \mathrm{MPa}$ (100 psi). The thickness of CFRP sheet was $1.5 \mathrm{~mm}$, which was consisted of 11 layers of prepreg with laying direction of $[0,90]$. The CFRP sheet was cut by water jet scalpel into $100 \times 25 \mathrm{~mm}^{2}$ substrates, where the length direction was consistent with the direction of the most top layer carbon fiber. The adhesive used in this study was two-component 3M DP460, which is a room-temperature-curing epoxy adhesive. The mechanical properties of cured 3M DP460 are listed in Table 3.

Table 1. Material properties of carbon fiber.

\begin{tabular}{ccccc}
\hline Material & $\begin{array}{c}\text { Fiber Diameter } \\
(\mu \mathbf{m})\end{array}$ & $\begin{array}{c}\text { Density } \\
\left(\mathbf{g} / \mathbf{c m}^{3}\right)\end{array}$ & $\begin{array}{c}\text { Tensile Strength } \\
(\mathbf{M P a})\end{array}$ & $\begin{array}{c}\text { Elongation } \\
(\mathbf{\%})\end{array}$ \\
\hline Carbon fiber & 7 & 1.76 & 3530 & 1.5 \\
\hline
\end{tabular}

Table 2. Material properties of epoxy resin.

\begin{tabular}{ccccc}
\hline Material & $\begin{array}{c}\text { Density } \\
\left(\mathrm{g} / \mathrm{cm}^{\mathbf{3}}\right)\end{array}$ & $\begin{array}{c}\text { Specific Heat } \\
\left(\mathrm{J} /\left(\mathbf{k g} \cdot{ }^{\circ} \mathbf{C}\right)\right)\end{array}$ & $\begin{array}{c}\text { Curing Temperature } \\
\left({ }^{\circ} \mathbf{C}\right)\end{array}$ & $\begin{array}{c}\text { Vaporization Temperature } \\
\left({ }^{\circ} \mathrm{C}\right)\end{array}$ \\
\hline Epoxy resin & 1.20 & 1000 & 120 & 250 \\
\hline
\end{tabular}

Table 3. Mechanical properties of fully cured 3M DP460 adhesive.

\begin{tabular}{ccccc}
\hline Adhesive & $\begin{array}{c}\text { Elastic Modulus } \\
\text { (GPa) }\end{array}$ & $\begin{array}{c}\text { Tensile Strength } \\
\text { (MPa) }\end{array}$ & $\begin{array}{c}\text { Shear Strength } \\
(\mathbf{M P a})\end{array}$ & $\begin{array}{c}\text { Elongation } \\
(\mathbf{\%})\end{array}$ \\
\hline 3M DP460 & 2.7 & 37 & 32 & 4 \\
\hline
\end{tabular}

\subsection{Plasma Treatment}

The operating frequency and voltage of the APPT equipment are $12 \mathrm{kHz}$ and $8 \mathrm{kV}$ respectively, and the waveform of the operating voltage is a sine wave. From Figure 1, it can be seen that plasma gas is jetted to the surface of CFRP substrate through a circular nozzle with a diameter of $4 \mathrm{~mm}$. Air was used as plasma gas in this study due to easy access, and the gas flow was set to $30 \mathrm{~L} / \mathrm{min}$. The motion trail of plasma nozzle relative to CFRP substrate is presented in Figure 2, where CFRP substrates were placed on an electronically-controlled platform. An area of $14 \times 25 \mathrm{~mm}^{2}$, slightly larger than the bond area $\left(12.5 \times 25 \mathrm{~mm}^{2}\right)$, was treated by APPT on CFRP substrates. In this study, the distance between plasma nozzle and CFRP substrate (nozzle distance, $h$ ) was set to $10 \mathrm{~mm}, 14 \mathrm{~mm}, 18 \mathrm{~mm}, 22 \mathrm{~mm}$ and $26 \mathrm{~mm}$, and the moving speed of plasma nozzle relative to CFRP substrate (nozzle speed, $v$ ) was set to $1 \mathrm{~mm} / \mathrm{s}, 3 \mathrm{~mm} / \mathrm{s}, 5 \mathrm{~mm} / \mathrm{s}, 7 \mathrm{~mm} / \mathrm{s}$ and $10 \mathrm{~mm} / \mathrm{s}$. The plasma treated CFRP joints were designated as $\mathrm{P}_{v-h}$ CFRP joints when the nozzle speed of $v$ and nozzle distance of $h$ were applied to the APPT. 


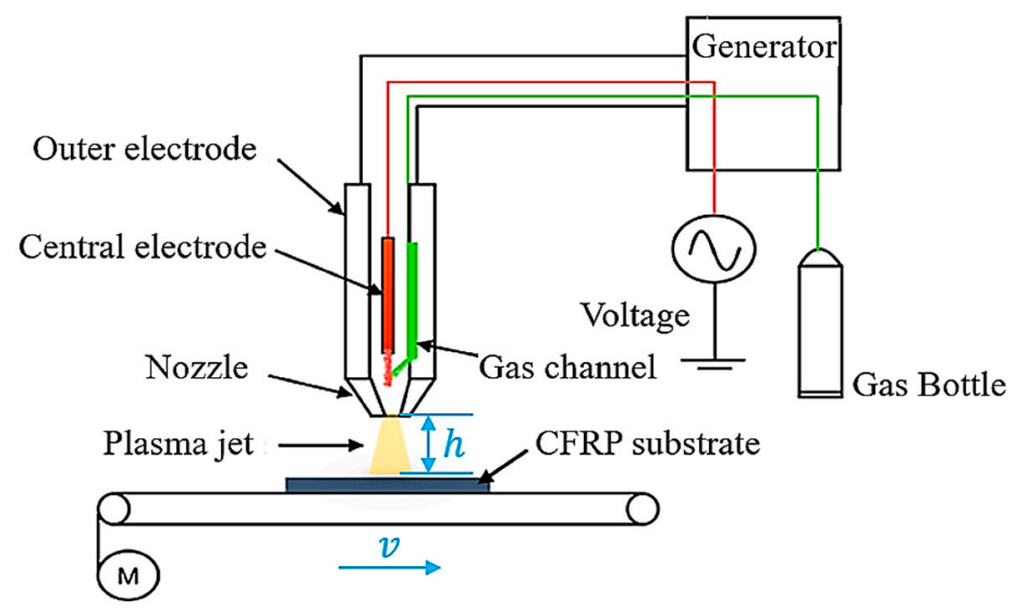

Figure 1. Diagrammatic sketch of the atmospheric pressure plasma treatment equipment.

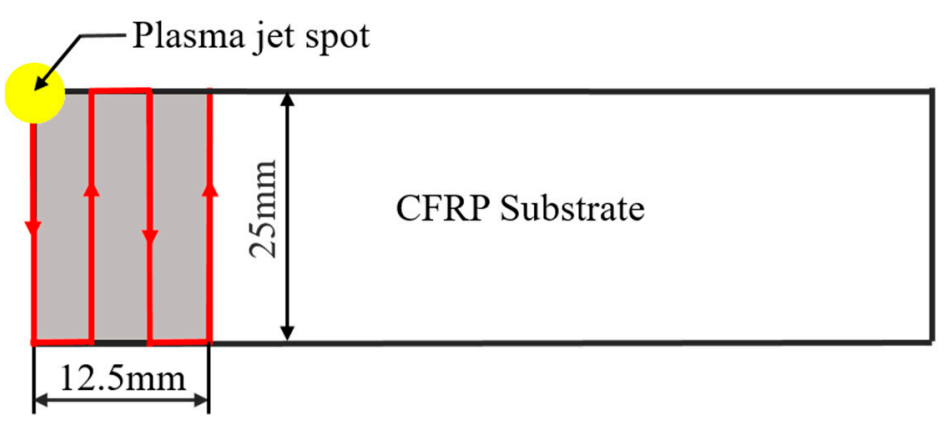

Figure 2. Illustration of the relative motion path between plasma jet and carbon fiber reinforced polymers (CFRP) substrate.

\subsection{Joint Fabrication}

The size of lap-shear adhesive-bonded joint sample is shown in Figure 3 and the fabrication processes are as follows: (1) Cleaning the bonding areas of two CFRP substrates with acetone; (2) Applying the adhesive onto the bonding area of either of the substrates by using an injection gun; (3) Scattering a layer of glass balls $(0.25 \mathrm{~mm}$ in diameter) on the adhesive surface to control the thickness of the adhesive layer; (The glass balls remain in the final adhesive-bonded joint.) (4) Applying pressure via the fixture and removing the excessive adhesive outside the bond area; (5) Examining joint quality to ensure the consistency of tensile testing results, and then curing the joints in an oven at $40{ }^{\circ} \mathrm{C}$ for $2 \mathrm{~h}$ per supplier's recommendation.

Unit in mm

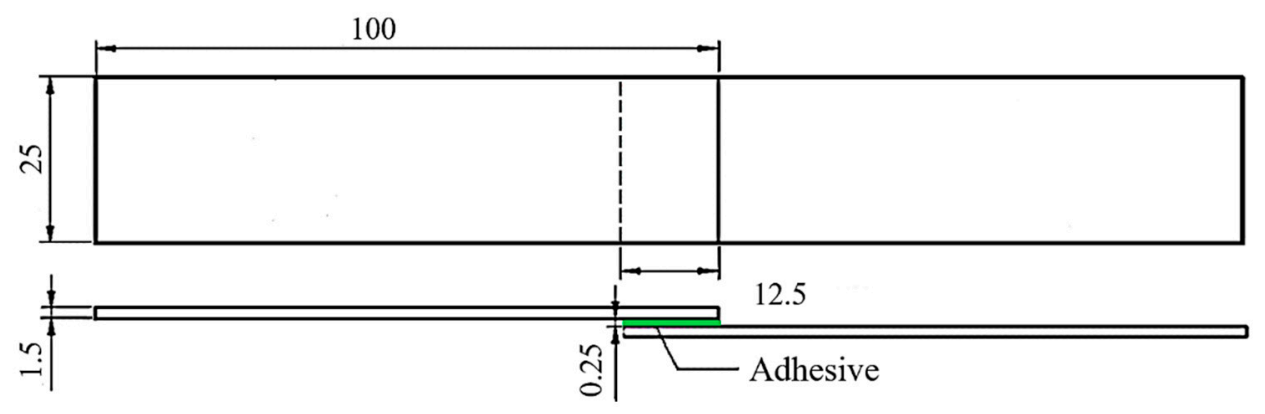

Figure 3. Configuration of the adhesive-bonded CFRP joint. 


\subsection{Quasi-Static Lap-Shear Tensile Test}

The quasi-static lap-shear tensile tests were carried out to measure joint strength according to the standard ASTM D1002-2001 [21]. The MTS E45.105 tensile tester was used to load CFRP adhesive-bonded joints to failure with a crosshead speed of $10 \mathrm{~mm} / \mathrm{min}$. Two filler plates were attached to both ends of the adhesive-bonded joint samples to minimize the effects of bending stress generated during the tensile test. The maximum load obtained from tensile tests was divided by the bond area to calculate the lap-shear strength of CFRP joints. The bond area of each joint was subject to the actual measurement and the maximum load was the average of five replicates.

\subsection{Temperature Measurements}

A thermal infrared imager (Optris-PI400) was used to measure CFRP substrate surface temperature via thermal radiation during APPT as shown in Figure 4. It can be connected to a computer via a USB connector and operated in Optris PI Connect software. The applied sampling frequency of the thermal infrared imager is $80 \mathrm{~Hz}$ and temperature measurement error is $2{ }^{\circ} \mathrm{C}$. The material emissivity of CFRP is 0.85 . In this study, the average temperature of the area directly under the nozzle (i.e., a circle with a diameter of $4 \mathrm{~mm}$ ) was used as the surface temperature of CFRP substrate during the APPT.

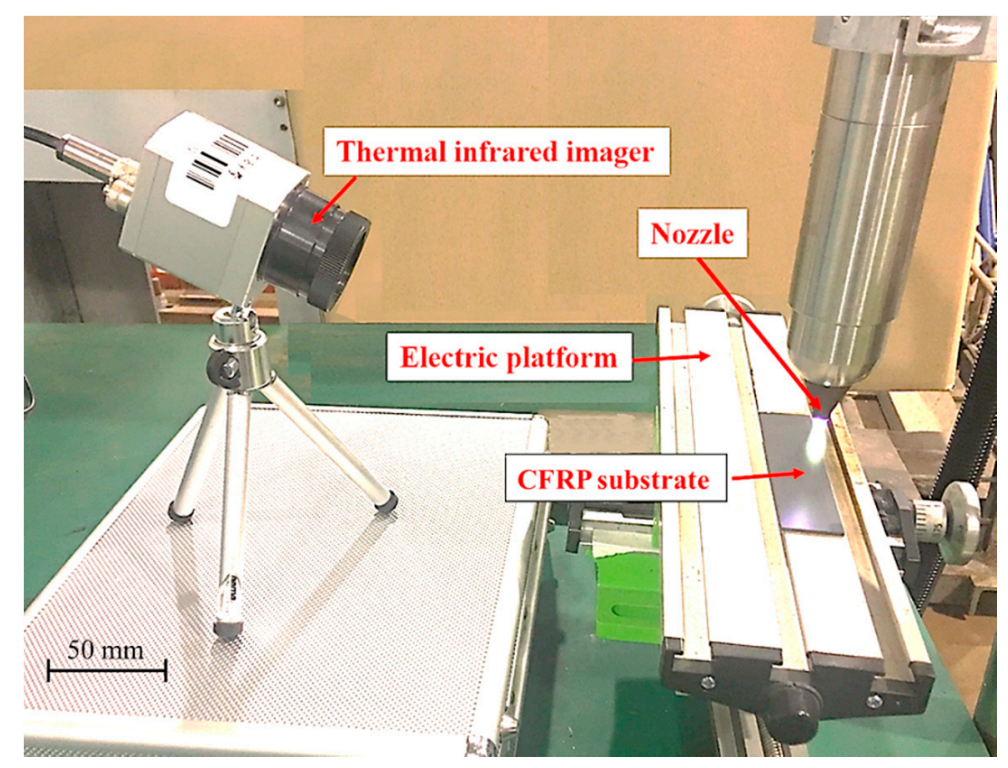

Figure 4. Measuring the surface temperature of a CFRP substrate during atmospheric pressure plasma treatment (APPT).

\subsection{Scanning Electron Microscope (SEM) Observation}

The surface morphologies of CFRP substrates were observed with a scanning electron microscope (SEM, Zeiss, Jena, Thuringia, Germany) at a voltage of $15 \mathrm{kV}$. As-received and plasma-treated CFRP substrates were cut into square specimens of $10 \times 10 \mathrm{~mm}^{2}$. A thin layer of gold was coated onto the specimen surfaces prior to SEM observation.

\subsection{X-ray Photo Spectroscopy (XPS) Tests}

The surface chemical composition of CFRP substrates was examined using a Thermo Fisher Scientific's ESCALAB 250 series X-ray photo electron spectroscopy (XPS, Thermo Fisher Scientific, Waltham, MA, USA). The apparatus used an $\mathrm{Al} \mathrm{K} \alpha$ monochromatic X-ray source and its analysis area was $900 \mu \mathrm{m}^{2}$. The base pressure and the energy resolution of the XPS test system were set to $4.3 \times 10^{-8} \mathrm{~Pa}$ and $0.44 \mathrm{eV}$, respectively. 


\subsection{Fourier Transform Infrared Spectroscopy (FTIR) Tests}

The evolution of functional groups on the surface of CFRP substrates caused by APPT was analyzed using a Nicolet's AVATAR 360 Fourier transform infrared spectroscopy (FTIR, Thermo Nicolet Corporation, Madison, WI, USA). Each sample was scanned for 32 times and the resolution was $4 \mathrm{~cm}^{-1}$. The infrared spectrum ranged from $400 \mathrm{~cm}^{-1}$ to $4000 \mathrm{~cm}^{-1}$.

\subsection{Contact Angle Measurements}

To investigate the effect of APPT on the surface wetting properties of CFRP substrates, Dataphysics OCA-20 contact-angle analyzer was used to measure contact angles of CFRP substrate surfaces. Three typical test liquids (i.e., Deionized water, diiodomethane and ethylene glycol) with known dispersion component and polar component [22], were selected to calculate the surface free energy of CFRP substrates. The volume of test liquid was controlled as $2 \mu \mathrm{L}$. The contact angles were read when the test liquid stabilized on the surface of CFRP substrate, and their values were averaged from three replicates.

\subsection{Differential Scanning Calorimetry (DSC) Tests}

Differential scanning calorimetry (DSC, TA Instruments, Newcastle, DE, USA) was tested on a TA Instruments DSC Q100 to investigate the chemical reaction temperature of epoxy resin. Epoxy resin with a weight of $4.810 \mathrm{mg}$ was placed in a hermetic crucible, and an empty crucible was used as a reference. The temperature range of quantitative dynamic scanning was from $0{ }^{\circ} \mathrm{C}$ to $250{ }^{\circ} \mathrm{C}$ at a heating rate of $10^{\circ} \mathrm{C} / \mathrm{min}$.

\subsection{Thermogravimetric Analysis (TGA)}

Thermogravimetric Analysis (TGA, TA Instruments, Newcastle, DE, USA) was used to investigate the weight change of CFRP as the temperature increases. CFRP substrate with a weight of $8.120 \mathrm{mg}$ was placed in a crucible and then put in a heating unit. The temperature range in the heating unit was from $20^{\circ} \mathrm{C}$ to $600{ }^{\circ} \mathrm{C}$ and the heating rate was $10^{\circ} \mathrm{C} / \mathrm{min}$.

\section{Results}

\subsection{Lap-Shear Tensile Testing Results}

To evaluate the effect of APPT on the bonding strength, adhesive bonded CFRP joints were fabricated and lap-shear tensile tests were conducted. Figure 5 presents the lap-shear strength of adhesive-bonded CFRP joints as a function of $v$ and $h$. It can be seen that the lap-shear strength of adhesive-bonded joints fabricated from as-received CFRP substrates was only 8.6 MPa. When $v$ was $1 \mathrm{~mm} / \mathrm{s}$, the lap-shear strength of adhesive-bonded joints fabricated from plasma-treated CFRP substrates ( $\mathrm{P}_{1-h}$ CFRP joints) increased from $21.2 \mathrm{MPa}$ to $30.5 \mathrm{MPa}$ as $h$ increased from $10 \mathrm{~mm}$ to $18 \mathrm{~mm}$. While $h$ was beyond $18 \mathrm{~mm}$, the lap-shear strength of plasma-treated CFRP joints decreased nearly linearly with an increase of $h$. Similar effect of $h$ on the lap-shear strength of $P_{v-h}$ CFRP joints was observed as $v$ was set to $5 \mathrm{~mm} / \mathrm{s}$, at which the lap-shear strength of $\mathrm{P}_{5-h} \mathrm{CFRP}$ joints reached a peak value of $31.6 \mathrm{MPa}$ when $h$ was $18 \mathrm{~mm}$. When $v$ was $10 \mathrm{~mm} / \mathrm{s}$, the lap-shear strength of $\mathrm{P}_{10-h}$ CFRP joints increased from 27.7 MPa to $29.7 \mathrm{MPa}$ as $h$ increased from $10 \mathrm{~mm}$ to $14 \mathrm{~mm}$, then decreased continuously with a further increase of $h$. Compared with the as-received CFRP joints, the lap-shear strength of $\mathrm{P}_{1-18}$ and $\mathrm{P}_{10-14}$ CFRP joints had an increase of $255 \%$ and $245 \%$, respectively, which are slightly lower than that of $\mathrm{P}_{5-18}$ CFRP joints (267\%). 


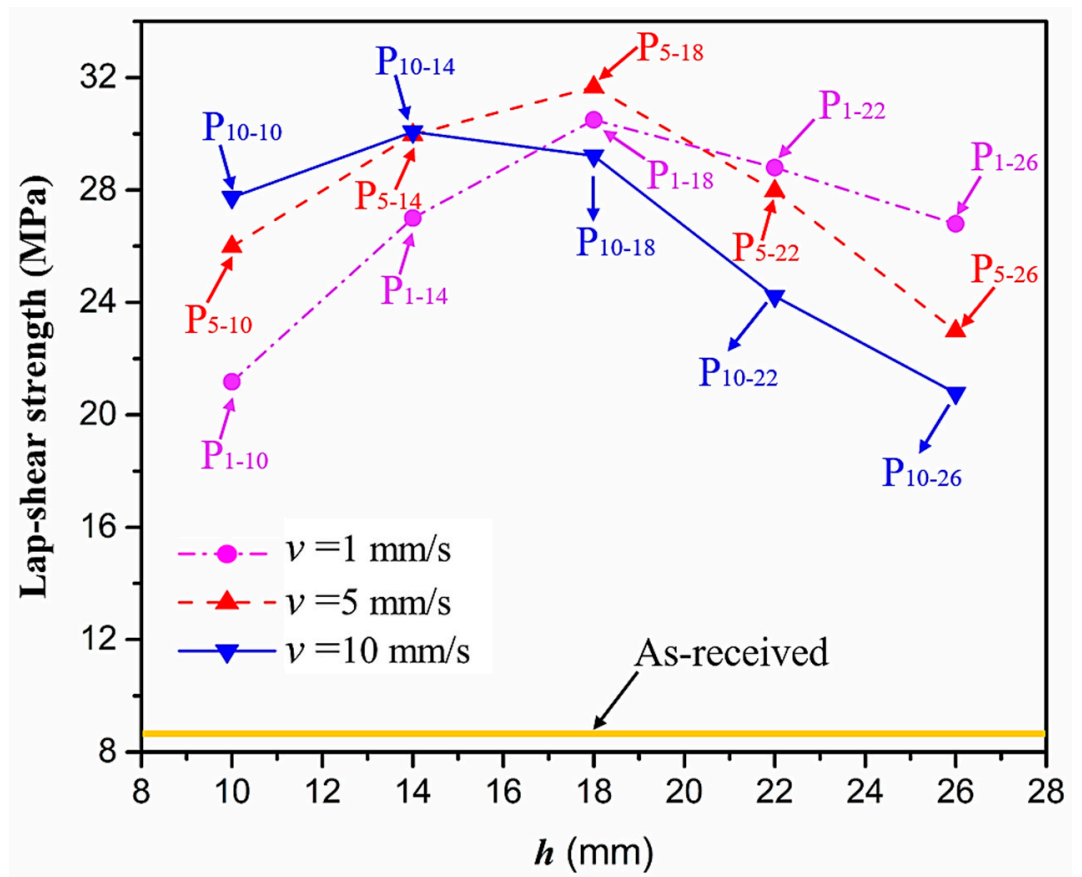

Figure 5. The lap-shear strength of adhesive-bonded CFRP joints as a function of the nozzle speed $(v)$ and the nozzle distance $(h)$.

In addition to the lap-shear strength, the fracture modes of adhesive-bonded joints are always regarded as an important aspect to evaluate their bonding performance. The fracture modes of plasma-treated CFRP joints can be classified into three scenarios: substrate failure (failure of CRFP substrate), cohesive failure (failure occurring inside the adhesive), and adhesive failure (failure at the interface between adhesive and substrate). Table 4 shows a schematic diagram of the three fracture modes and Table 5 listed the fracture modes of all plasma-treated CFRP joints after lap-shear tensile testing. From Table 5, it can been seen that the fracture modes of $\mathrm{P}_{1-10}, \mathrm{P}_{1-14}, \mathrm{P}_{1-18}, \mathrm{P}_{5-10}, \mathrm{P}_{5-14}, \mathrm{P}_{10-10}$, and $\mathrm{P}_{10-14} \mathrm{CFRP}$ joints were substrate failure, where a layer of broken carbon fibers was stuck on the adhesive. Therefore, the lap-shear strength of joints was dominated by the strength of the CFRP substrate. The fracture mode of $\mathrm{P}_{5-18} \mathrm{CFRP}$ joint was cohesive failure. For the cohesive failure, the lap-shear strength of adhesive bonded joints was mainly dependent on the shear strength of adhesive, which indicates that it is not necessary to continue to activate the CFRP substrate surface since the interfacial bonding strength between adhesive and CFRP substrate is higher than the shear strength of adhesive. The fracture modes of $\mathrm{P}_{1-22}, \mathrm{P}_{1-26}, \mathrm{P}_{5-22}, \mathrm{P}_{5-26}, \mathrm{P}_{10-18}, \mathrm{P}_{10-22}$, and $\mathrm{P}_{10-26} \mathrm{CFRP}$ joints were adhesive failure similar to that of the as-received CFRP joints. In this case, the lap-shear strength of adhesive bonded joints was dominated by the interfacial bonding strength between the adhesive and CFRP substrate. The lap-shear strength of adhesive bonded joints in the case of cohesive failure was higher than the failure of the CFRP substrate, which may be due to thermal damage (i.e., pyrolysis carbonization of resin matrix) introduced to the CFRP substrate caused by APPT as smaller $h$ and lower $v$ were applied $[23,24]$.

Table 4. Schematic diagram of fracture modes.

\begin{tabular}{cccc}
\hline Fracture Modes & Substrate Failure & Cohesive Failure \\
\hline Schematic diagrams & & \\
\hline
\end{tabular}


Table 5. Fracture modes of plasma-treated CFRP joints.

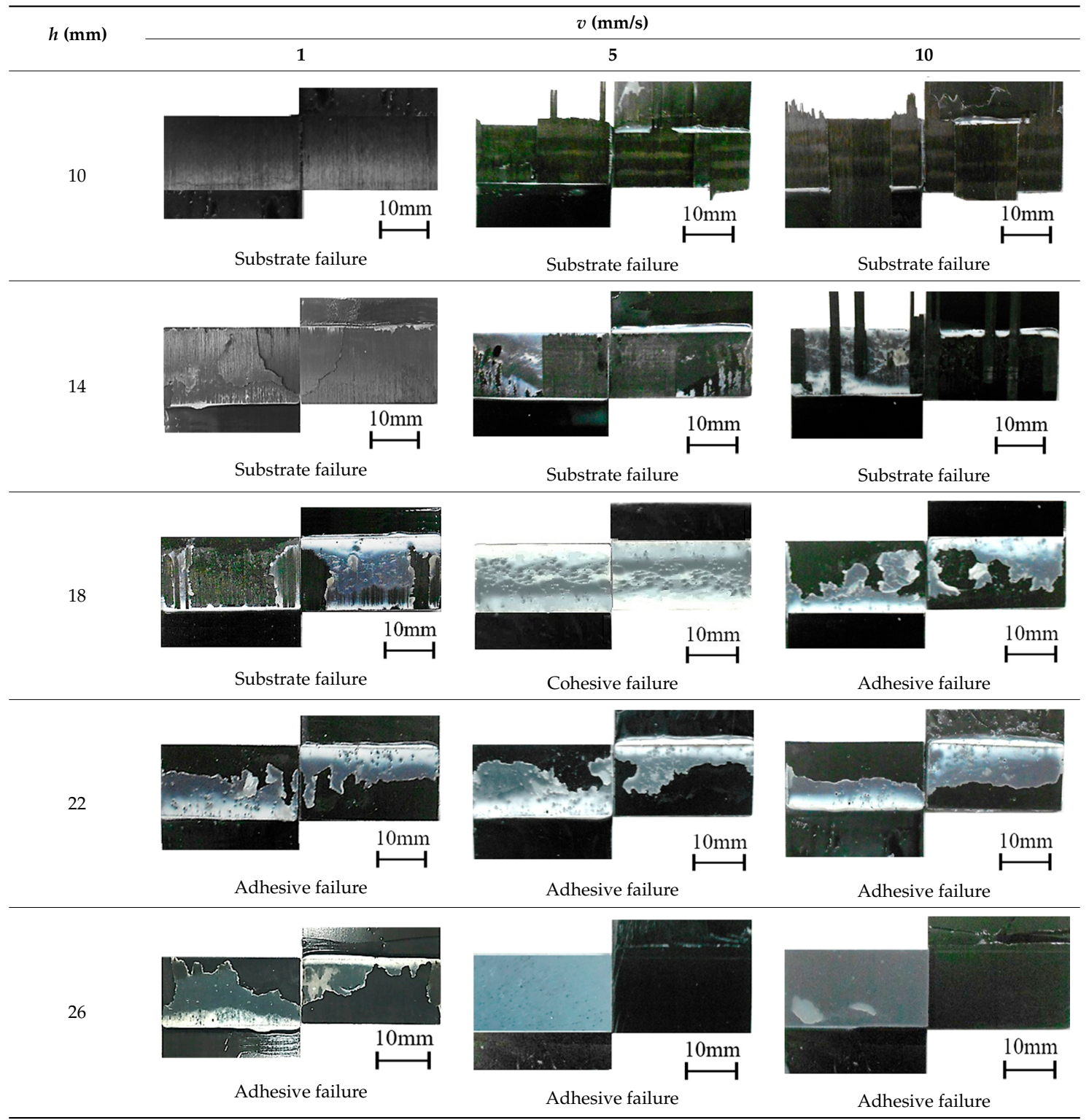

\subsection{Temperature Measurement Results}

In order to understand how the plasma processing parameters affect the surface temperature of CFRP substrate ( $T$ ), $T$ was measured by a thermal infrared imager when the CFRP substrate was treated by plasma equipment with different $v$ and $h$, and the measured temperatures $\left(T_{\exp }\right)$ are presented in Figure 6. From Figure 6, it can be seen that the highest $T_{\exp }$ occurred at the smallest $h$ and the lowest $v$. It is found that $h$ showed a more significant effect on the $T_{\exp }$ than $v$. When $v$ was $1 \mathrm{~mm} / \mathrm{s}$, $T_{\text {exp }}$ decreased from $538{ }^{\circ} \mathrm{C}$ to $132{ }^{\circ} \mathrm{C}$ as the $h$ increased from $10 \mathrm{~mm}$ to $26 \mathrm{~mm}$. When $h$ was $10 \mathrm{~mm}$, the $T_{\exp }$ decreased from $538{ }^{\circ} \mathrm{C}$ to $437^{\circ} \mathrm{C}$ as the $v$ increased from $1 \mathrm{~mm} / \mathrm{s}$ to $10 \mathrm{~mm} / \mathrm{s}$. In addition, the effect of $v$ on the $T_{\exp }$ decreased with increasing $h$. When $h$ was $26 \mathrm{~mm}$, the $T_{\exp }$ decreased by only $30{ }^{\circ} \mathrm{C}$ as the $v$ increased from $1 \mathrm{~mm} / \mathrm{s}$ to $10 \mathrm{~mm} / \mathrm{s}$. It is found that $T$ can be expressed as an function of $h$ and $v$, i.e., Equation (1), and the goodness of fit for $T$ is characterized by the mean square root (MSR) error and maximum deviation (MD). Based on Equations (2) and (3), the MSR error and MD between the calculated temperature by Equation (1) $T_{\text {cal }}$ and $T_{\text {exp }}$ is $5.3^{\circ} \mathrm{C}$ and $9.0^{\circ} \mathrm{C}$, respectively. 
Figure 7 shows that the empirical model (Equation (1)) is capable of providing a satisfied prediction to the surface temperature of CFRP substrate at least within the investigated ranges of $v$ and $h$.

$$
\begin{gathered}
T=\left(-5.90 * 10^{-3} * h^{3}+3.24 * 10^{-1} * h^{2}-5.05 * h+12.71\right) * v-1.54 * 10^{-1} * h^{3} \\
+1.04 * 10^{1} * h^{2}-2.40 * 10^{2} * h+2.06 * 10^{3} \\
\text { MSR }=\sqrt{\frac{1}{25} * \sum_{n=1}^{n=25}\left(T_{\text {cal }}-T_{\text {exp }}\right)^{2}} \\
\text { MD }=\operatorname{Max} \sum_{n=1}^{n=25}\left|T_{\text {cal }}-T_{\exp }\right|
\end{gathered}
$$

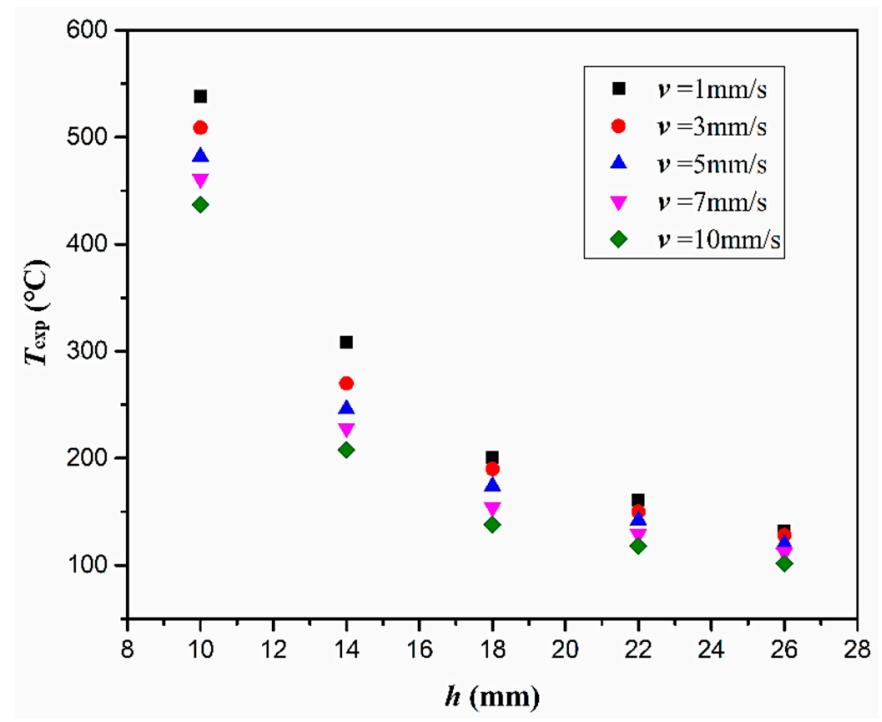

Figure 6. The measured temperature of CFRP substrate surface $\left(T_{\exp }\right)$ as a function of nozzle speed $(v)$ and nozzle distance $(h)$.

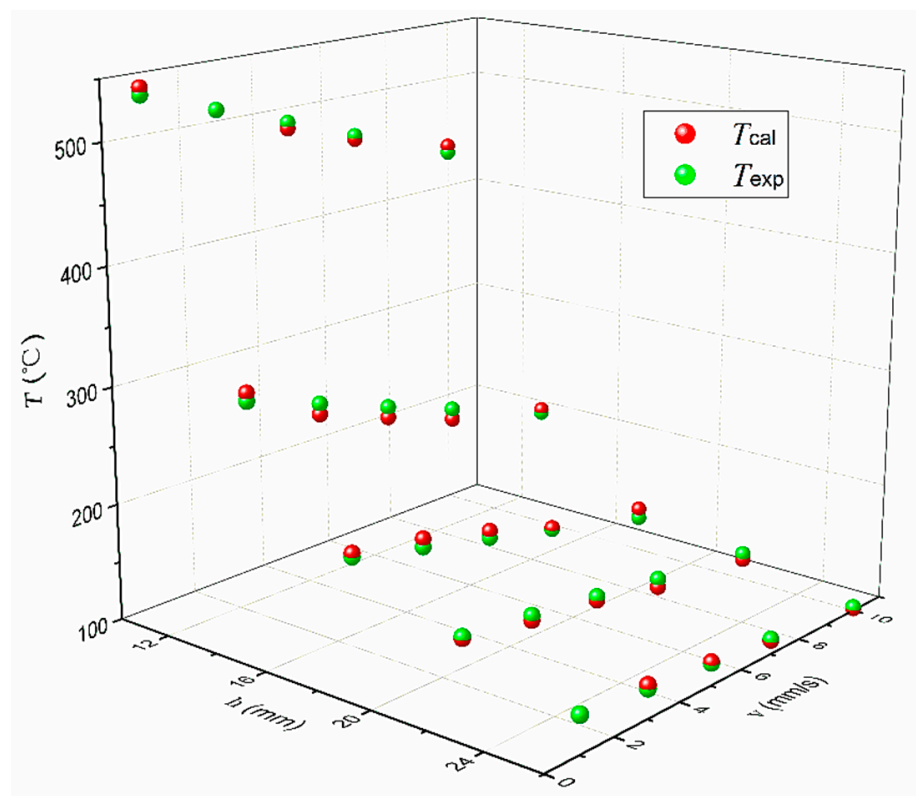

Figure 7. Deviation between the calculated temperature by Equation (1) ( $\left.T_{\text {cal }}\right)$ and the experimentally measured temperature $\left(T_{\exp }\right)$ of CFRP substrates surface. 


\subsection{Surface Morphologies of CFRP Substrates}

To examine the morphological changes in the surface of plasma-treated CFRP substrate, scanning electron microscopy (SEM) observations were performed. Figure $8 \mathrm{a}-\mathrm{f}$ present the surface morphologies of the as-received and plasma-treated CFRP substrates (i.e., $\mathrm{P}_{5-10}, \mathrm{P}_{5-14}, \mathrm{P}_{5-18}, \mathrm{P}_{10-14}$, and $\mathrm{P}_{10-18} \mathrm{CFRP}$ substrates). From Figure $8 \mathrm{a}$, it can be found that the surface of as-received CFRP substrate is relatively homogeneous and smooth, but there are some tiny pores having a diameter of smaller than $2 \mu \mathrm{m}$ on the surface of the epoxy resin. When $v$ of $5 \mathrm{~mm} / \mathrm{s}$ and $h$ of $10 \mathrm{~mm}$ were applied to treating CFRP substrate, it can be observed from Figure $8 b$ that the epoxy resin on the surface of $P_{5-10}$ CFRP substrate (with $T_{\exp }=482^{\circ} \mathrm{C}$ ) was removed and carbon fibers on the outermost layer were exposed and had minor damage. A lot of pores larger than $5 \mu \mathrm{m}$ in diameter on the epoxy resin of $\mathrm{P}_{5-14}$ (with $T_{\exp }=246{ }^{\circ} \mathrm{C}$ ) and $\mathrm{P}_{10-14}$ (with $T_{\exp }=208^{\circ} \mathrm{C}$ ) CFRP substrates were observed, as shown in Figure $8 \mathrm{c}, \mathrm{d}$, respectively. Some scholars have reported that double bonds can be formed by eliminating water in epoxy resin molecules at the temperature higher than $120^{\circ} \mathrm{C}$ [25], which may create larger and deeper pores on the original pores or create new pores in the surface of the epoxy resin. The surface morphologies of $\mathrm{P}_{5-18}$ (with $T_{\exp }=174{ }^{\circ} \mathrm{C}$ ) and $\mathrm{P}_{10-18}$ (with $T_{\exp }=138^{\circ} \mathrm{C}$ ) CFRP substrates were nearly the same as that of the as-received CFRP substrate shown in Figure 8e,f. Therefore, it is suggested that there is little thermal damage occurred on the CFRP substrates when the surface temperature of CFRP substrate during APPT is below $174{ }^{\circ} \mathrm{C}$.

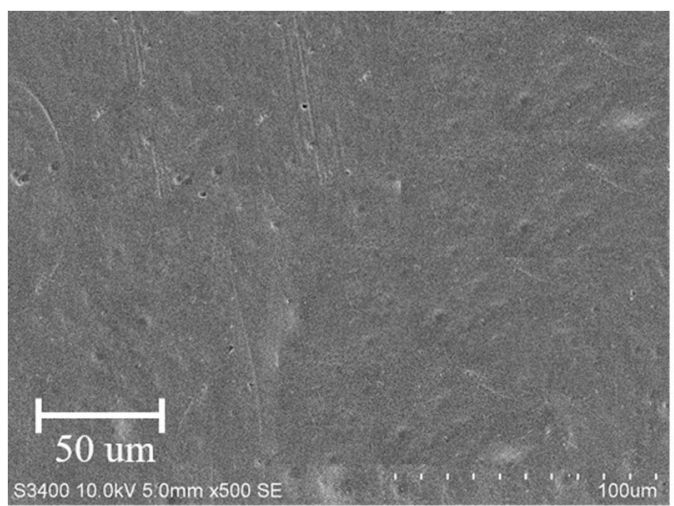

(a)

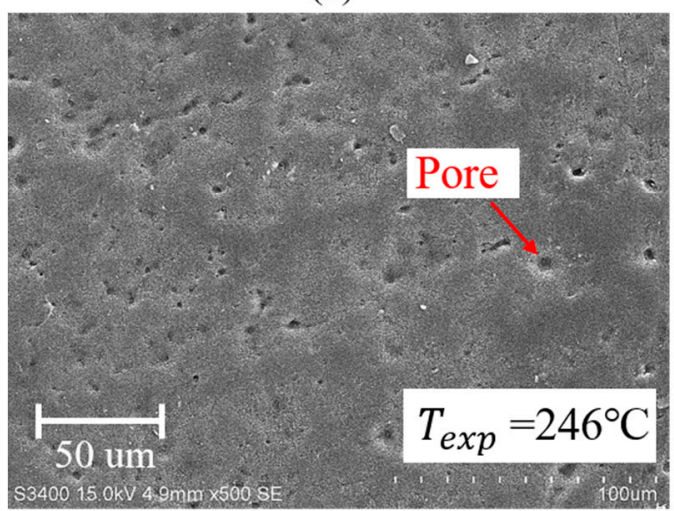

(c)

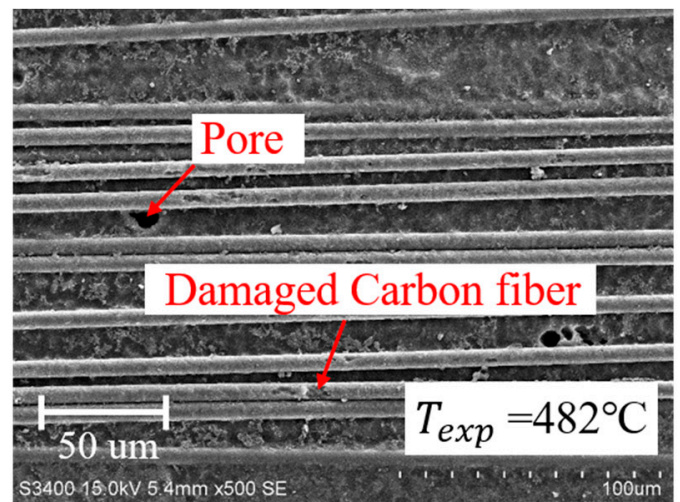

(b)

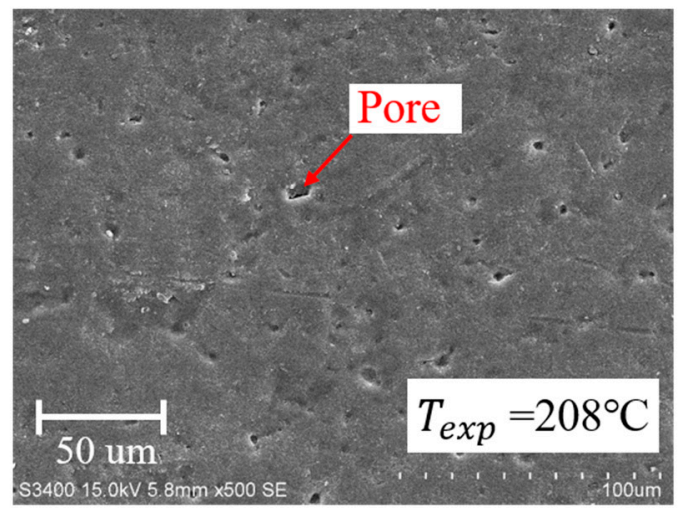

(d)

Figure 8. Cont. 


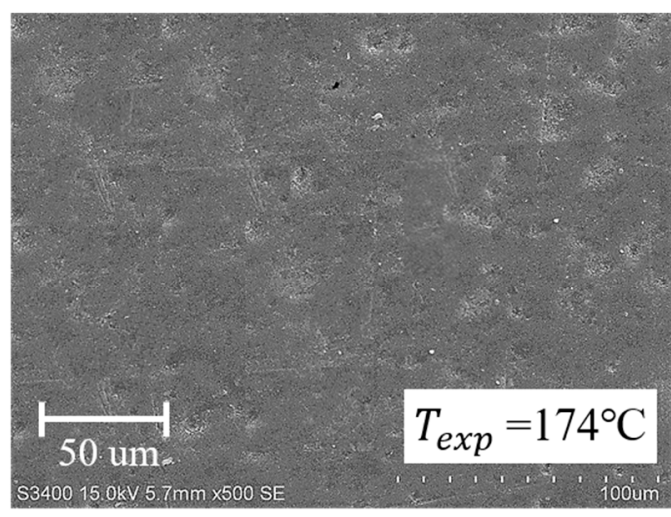

(e)

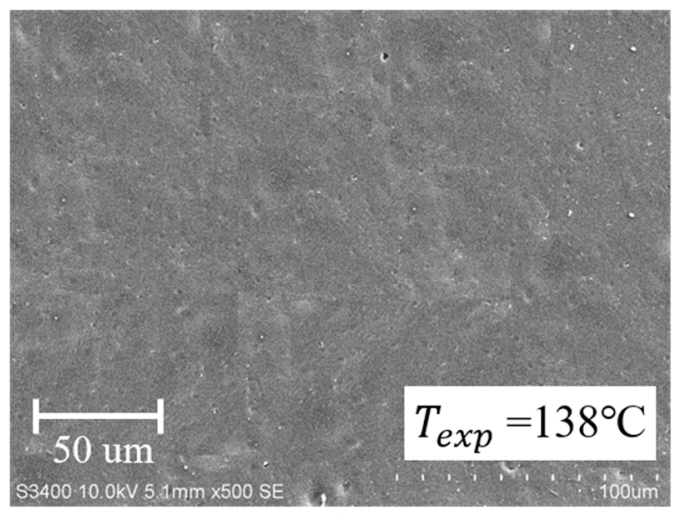

(f)

Figure 8. SEM images of (a) the as-received CFRP substrate surface and plasma-treated CFRP substrate surfaces of (b) $\mathrm{P}_{5-10}$, (c) $\mathrm{P}_{5-14}$, (d) $\mathrm{P}_{10-14}$, (e) $\mathrm{P}_{5-18}$, and (f) $\mathrm{P}_{10-18}$.

\subsection{Surface Chemistries of CFRP Substrates}

To study the chemical element changes caused by APPT on CFRP substrates, X-ray photoelectron spectroscopy (XPS) was used to detect the surface chemical compositions of the as-received and plasma-treated CFRP substrates (i.e., $\mathrm{P}_{5-18}, \mathrm{P}_{10-18}$, and $\mathrm{P}_{5-26}$ CFRP substrates). Figure 9 presents the high resolution XPS scanning results of Si2s, Si2p, C1s, N1s, and O1s. The content of each element of interest is listed in Table 6. It can be seen from the table that compared with the as-received substrate, the content of $\mathrm{Si}$ element on the $\mathrm{P}_{5-18}, \mathrm{P}_{10-18}$ and $\mathrm{P}_{5-26} \mathrm{CFRP}$ substrate surfaces was reduced by $70 \%$, $51 \%$, and $15 \%$ after APPT, respectively. The Si element, mainly existing in the form of $-\left(\mathrm{CH}_{3}\right)_{2} \mathrm{Si}-\mathrm{O}-$, is one of the components of the release agent, which acts as surface contamination on the CFRP substrate blocking the bonding of the adhesive and epoxy resin [26]. From the reduced Si contents on the plasma-treated CFRP substrate surfaces, the contaminations on the CFRP substrate surface can be removed more completely by APPT when a smaller $h$ or a slower $v$ was applied. Comparing the contents of $\mathrm{O}$ and $\mathrm{N}$ elements on the $\mathrm{P}_{5-18}$ and $\mathrm{P}_{5-26}$ CFRP substrate surfaces, it can be found that when $h$ was increased from $18 \mathrm{~mm}$ to $26 \mathrm{~mm}$, the contents of oxygen and nitrogen dropped by $56 \%$ and $45 \%$. While $h$ was fixed at $18 \mathrm{~mm}$ and $v$ was increased from $5 \mathrm{~mm} / \mathrm{s}$ to $10 \mathrm{~mm} / \mathrm{s}$, it is observed that the contents of oxygen and nitrogen dropped by $21 \%$ and $39 \%$. This suggests that the increase of either $h$ or $v$ results in reducing the contents of both oxygen and nitrogen on the plasma-treated CFRP substrate surface.

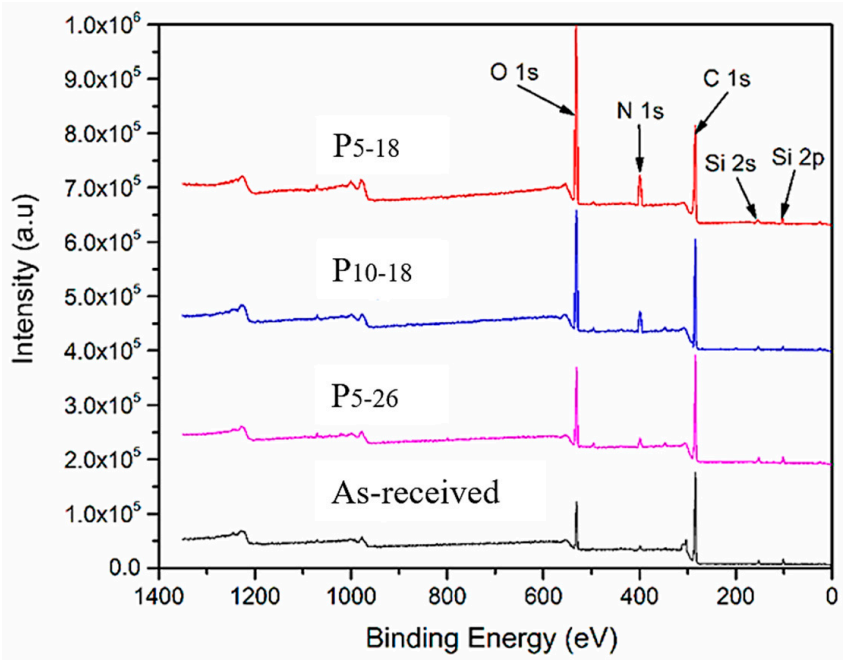

Figure 9. X-ray photoelectron spectroscopy (XPS) spectra showing the effect of plasma treatment process parameters on the surface chemistry of CFRP substrate. 
Table 6. The chemical compositions of CFRP substrate surfaces.

\begin{tabular}{|c|c|c|c|c|c|}
\hline Chemical Ele & at (wt \%) & $\mathrm{C}$ & $\mathbf{O}$ & $\mathbf{N}$ & $\mathrm{Si}$ \\
\hline \multirow{4}{*}{ CFRP substrates } & As-received & 74.61 & 17.69 & 3.92 & 3.41 \\
\hline & $P_{5-18}$ & 63.72 & 28.88 & 5.68 & 1.02 \\
\hline & $P_{10-18}$ & 67.94 & 25.12 & 4.16 & 1.66 \\
\hline & $P_{5-26}$ & 72.99 & 18.93 & 3.93 & 2.89 \\
\hline
\end{tabular}

Figure 10 shows the carbon functional groups XPS analyses of the as-received and plasma-treated (i.e., $\mathrm{P}_{5-18}$ CFRP substrates, the chemical element change on the surface is most obvious) CFRP substrates surface. The peaks at $288.7 \mathrm{eV}$ and $286.2 \mathrm{eV}$ are attributed to $\mathrm{C}=\mathrm{O}$ (or $\mathrm{O}-\mathrm{C}=\mathrm{O}$ ) and $\mathrm{C}-\mathrm{O}$ (or $\mathrm{C}-\mathrm{N}$ ), respectively, and the peak at $284.7 \mathrm{eV}$ is representative of $\mathrm{C}-\mathrm{C}$ (or $\mathrm{C}-\mathrm{H}$ ). Table 7 shows the content of carbon functional groups. It can be observed that after APPT with $v=5 \mathrm{~mm} / \mathrm{s}$ and $h=18 \mathrm{~mm}$, the $\mathrm{C}=\mathrm{O} / \mathrm{O}-\mathrm{C}=\mathrm{O}$ bond content of CFRP substrate surface was increased by $118.4 \%$, the $\mathrm{C}-\mathrm{O} / \mathrm{C}-\mathrm{N}$ bond content of CFRP substrate surface was increased by $139.5 \%$, while the $\mathrm{C}-\mathrm{C} / \mathrm{C}-\mathrm{H}$ bond content of CFRP substrate surface was decreased by $31.7 \%$.

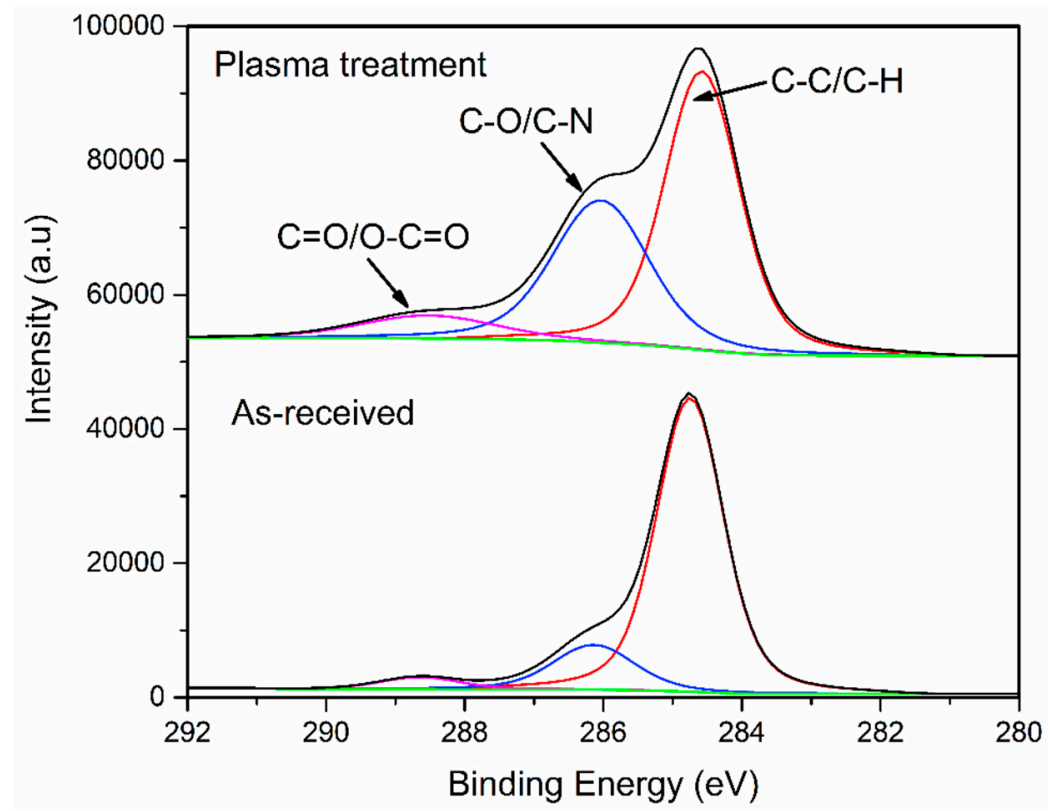

Figure 10. High resolution XPS scans of $C 1 \mathrm{~s}$ on the as-received and plasma-treated $\left(\mathrm{P}_{5-18}\right) \mathrm{CFRP}$ substrate surfaces.

Table 7. XPS peak fitting method describing carbon functional group distribution.

\begin{tabular}{ccccc}
\hline \multicolumn{2}{c}{ Functional Groups (wt \%) } & $\mathbf{C}=\mathbf{O} / \mathbf{O}-\mathbf{C}=$ & $\mathbf{C}-\mathbf{O} / \mathbf{C}-\mathbf{N}$ & $\mathbf{C}-\mathbf{C} / \mathbf{C}-\mathbf{H}$ \\
\hline \multirow{2}{*}{ CFRP substrates } & As-received & 3.8 & 15.2 & 81.0 \\
\cline { 2 - 5 } & $\mathrm{P}_{5-18}$ & 8.3 & 36.4 & 55.3 \\
\hline
\end{tabular}

FTIR was performed to further analyze surface modifications of plasma-treated CFRP substrates as well as to identify what functional groups contribute to improve interface bond strength. Except for the observed differences within the range from 2600 to $3800 \mathrm{~cm}^{-1}$, the overall absorbance of $P_{5-18}$ CFRP substrate surface was almost the same with the as-received substrate surface. Figure 11 presents a compilation of the spectra as an effect of APPT within this range. The absorption between 2800 and $3000 \mathrm{~cm}^{-1}$ is related to $-\mathrm{CH}_{3}$, which is typically quite stable on the surface of the as-received CFRP substrate even after curing process of CFRP sheet or acetone-cleaning. However, after APPT 
$-\mathrm{CH}_{3}$ groups appeared to become oxidized and the intensity decreased. In addition, the absorptions at $3500 \mathrm{~cm}^{-1}$ and $3300 \mathrm{~cm}^{-1}$ are associated with $-\mathrm{OH}$ and $-\mathrm{NH}_{2}$, and both had a significant increase in intensity.

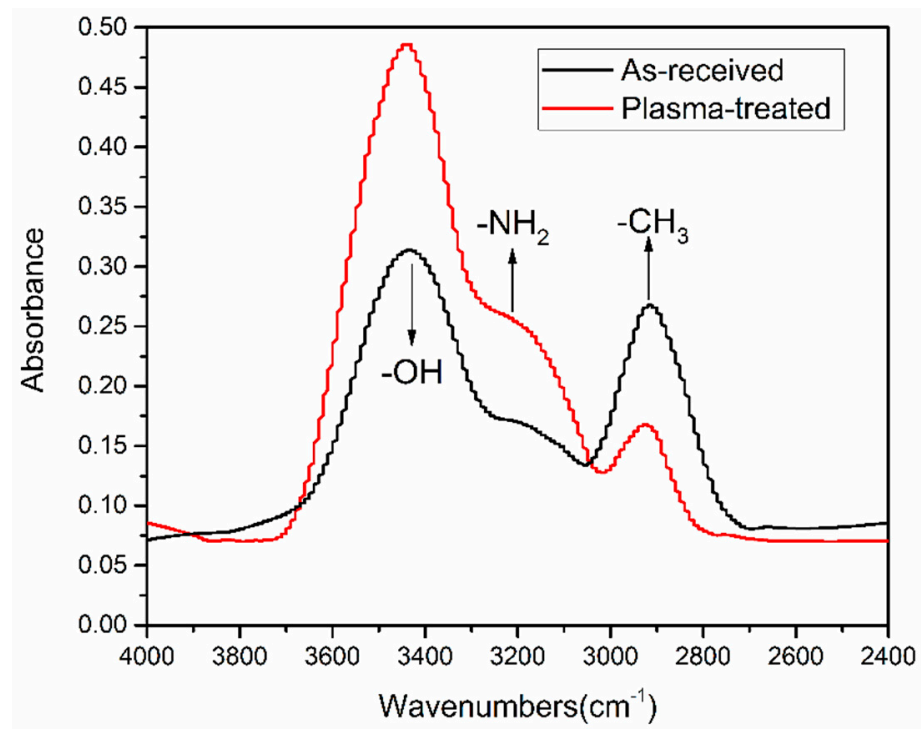

Figure 11. FTIR spectra of the as-received and plasma-treated $\left(\mathrm{P}_{5-18}\right) \mathrm{CFRP}$ substrates.

\subsection{Wettability of CFRP Substrates}

To examine the effect of APPT on wetting characteristics of CFRP substrates, the contact angles of as-received and $\mathrm{P}_{5-18} \mathrm{CFRP}$ substrates were compared. Before measuring contact angles, as-received CFRP substrates were cleaned with acetone and dried in laboratory environment. The wettability of CFRP substrates can be evaluated through the measured contact angles of the substrate surfaces [27]. As listed in Table 8, APPT decreased the contact angles for all test liquids (i.e., distilled water, ethylene glycol, and diiodomethane). When distilled water was used as the test liquid, the contact angles of as-received and $\mathrm{P}_{5-18} \mathrm{CFRP}$ substrates were presented in Figure 12. The contact angle of the as-received CFRP substrate was measured as $108.6^{\circ}$, while the contact angle decreases to $32.4^{\circ}$ after APPT with $v=5 \mathrm{~mm} / \mathrm{s}$ and $h=18 \mathrm{~mm}$ (i.e., the $\mathrm{P}_{5-18}$ CFRP substrate). These results indicate that the surfaces of CFRP substrates became more hydrophilic after APPT. Similar experimental phenomena were observed in previous reports [28,29].

To further evaluate surface wetting properties, the surface free energy (SFE) of CFRP substrates, expressed by Equation (4), was calculated based on the Owens-Wendt method [30,31]. Figure 13 presents the surface free energy consisted of corresponding polar and dispersion components. The SFE of the $\mathrm{P}_{5-18}$ CFRP substrate increased significantly compared to the as-received substrate, which agrees well with the reported results based on other plasma pretreatment methods [32]. The SFE of the $\mathrm{P}_{5-18}$ CFRP substrate reached up to $61.33 \mathrm{~mJ} / \mathrm{m}^{2}$ and was enhanced by $36.81 \mathrm{~mJ} / \mathrm{m}^{2}$ compared to that of the as-received CFRP substrate. Referring to Figure 13, the enhancement of SFE of the $\mathrm{P}_{5-18}$ CFRP substrate is mainly due to the increase of its polar component.

$$
\gamma_{L}(1+\cos \alpha)=2 \sqrt{\gamma_{S}^{d} \gamma_{L}^{d}}+2 \sqrt{\gamma_{S}^{p} \gamma_{L}^{p}}
$$

In the Equation (4), $\gamma_{L}$ represents the surface energy of test liquids, $\gamma_{L}^{d}$ and $\gamma_{L}^{p}$ are dispersion and polar components of $\gamma_{L}$, respectively; $\gamma_{S}$ represents the surface energy of CFRP substrate, $\gamma_{S}^{d}$ and $\gamma_{S}^{p}$ are dispersion and polar components of $\gamma_{S}$, respectively; and $\alpha$ represents the measured contact angle. 
Table 8. Measured contact angles of the as-received and $\mathrm{P}_{5-18}$ CFRP substrates.

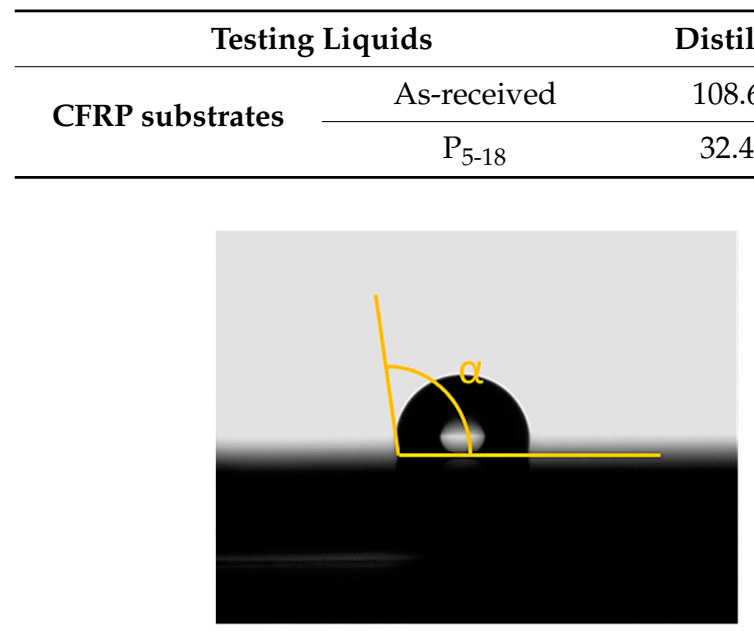

(a)

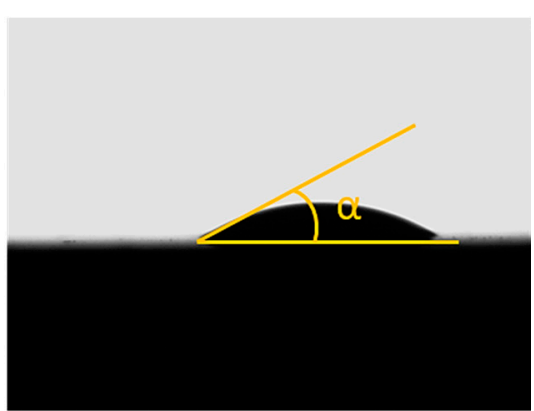

(b)

Figure 12. The contact angles of distilled water measured for (a) the as-received and (b) plasma-treated $\left(\mathrm{P}_{5-18}\right)$ CFRP substrates.

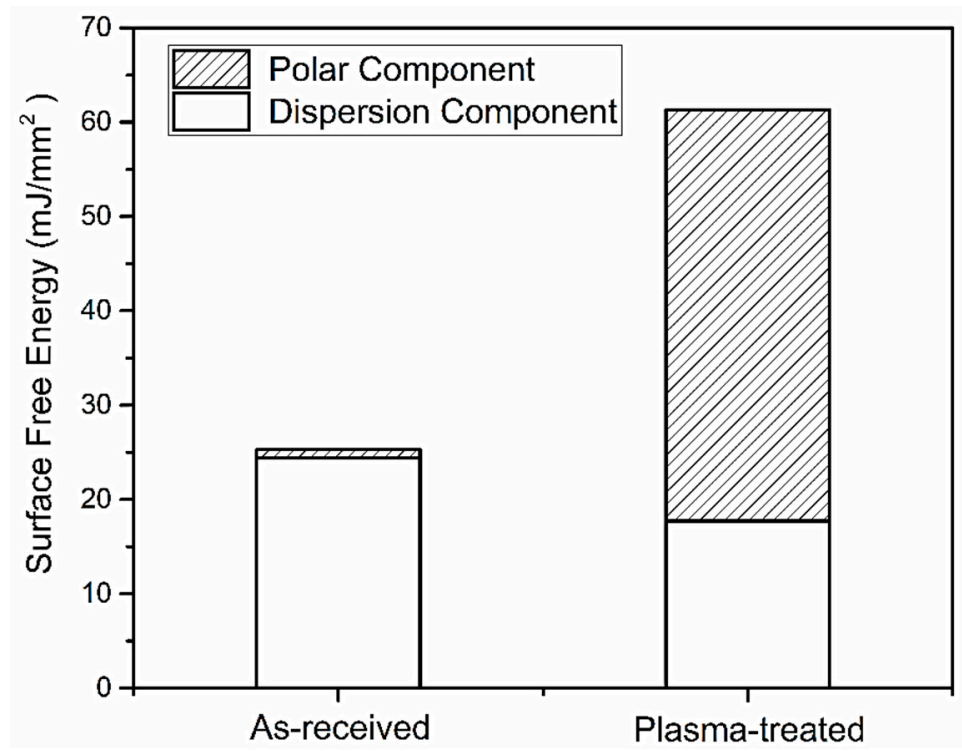

Figure 13. The surface free energies of the as-received and plasma-treated $\left(\mathrm{P}_{5-18}\right) \mathrm{CFRP}$ substrates.

\subsection{Thermal Damage Temperature of CFRP Substrates}

To study the effect of temperature on the CFRP substrate, the epoxy resin of CFRP was tested by DSC. The DSC testing result is presented in Figure 14. From Figure 14, it can be seen that the cured epoxy resin has an endothermic peak at $194.5^{\circ} \mathrm{C}$ and the initial temperature of the endothermic peak is $175.3^{\circ} \mathrm{C}$. This indicates that the epoxy resin started to react chemically as the temperature reached $175.3^{\circ} \mathrm{C}$. Figure 15 presents the weight of CFRP substrate $(\mathrm{m})$ changes as a function of temperature. The weight of the CFRP substrate started to decrease as the temperature was above $T_{1}$ $\left(\sim 170{ }^{\circ} \mathrm{C}\right)$. When the temperature reached $T_{2}\left(\sim 340{ }^{\circ} \mathrm{C}\right)$, the epoxy resin in the CFRP substrate was almost fully pyrolysed. 


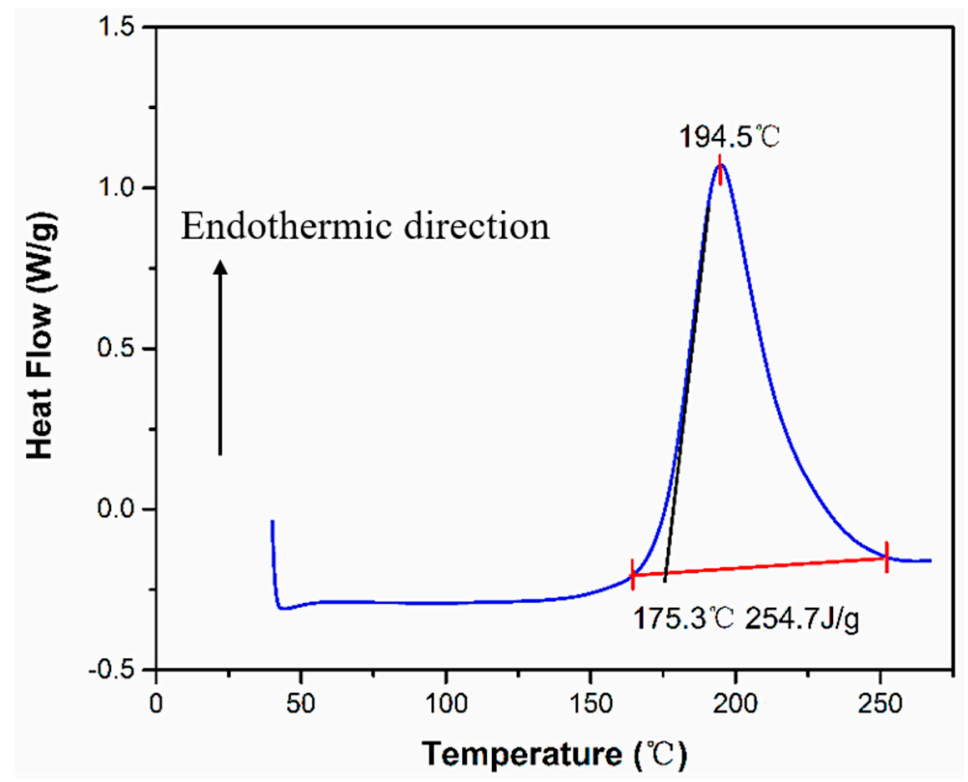

Figure 14. Differential scanning calorimetry (DSC) thermogram of the CFRP epoxy resin.

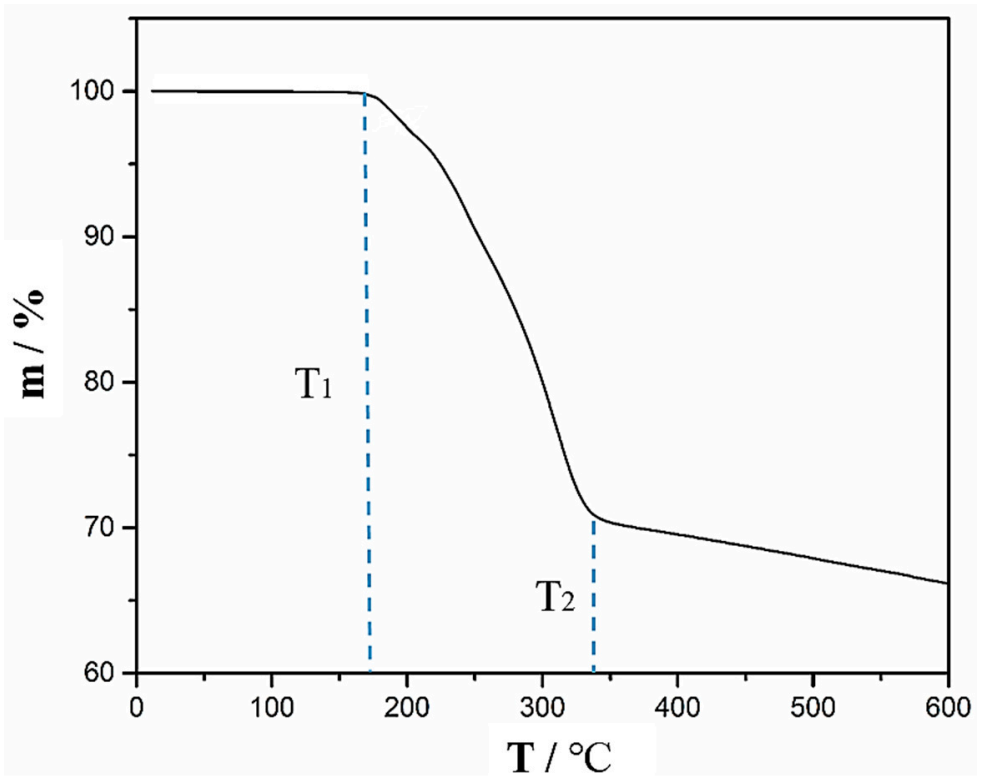

Figure 15. Thermogravimetric Analysis (TGA) showing the change of CFRP substrate weight with increasing temperature.

\section{Discussion}

From the above results, the mechanism accounting for the improved lap-shear strength of CFRP adhesive bonded joints through APPT is discussed here. On the one hand, APPT has a cleaning effect of surface contaminations on the CFRP substrates. Compared to the as-received CFRP substrate, the content of Si element on the plasma-treated CFRP substrate surface was decreased significantly. In addition, the $-\mathrm{CH}_{3}$ groups, which are unfavorable for adhesive bonding as non-polar groups [33], were oxidized or removed after APPT. These indicate that there was a layer of release agent remaining on the surface of the as-received CFRP, of which the main component is - $\left(\mathrm{CH}_{3}\right)_{2} \mathrm{Si}-\mathrm{O}-$ that cannot be removed by acetone cleaning. Release agent is an inert substance blocking the bond between the adhesive and CFRP substrate, which has been reported resulting in low bonding strength and adhesive failure of as-received CFRP joint [26]. Therefore, the lap-shear strength of adhesive bonded joints increased after removing the release agent by APPT. On the other hand, APPT generates many 
polar groups such as $-\mathrm{OH},-\mathrm{COOH}$, and $-\mathrm{NH}_{2}$ on the surface of CFRP substrates. Compared to the as-received CFRP substrate, APPT increased the contents of $\mathrm{O}$ and $\mathrm{N}$ elements on the plasma-treated CFRP substrate surface. Further analysis revealed that the $\mathrm{O}$ element mainly exists in the form of $-\mathrm{OH}$ and $-\mathrm{COOH}$, while the $\mathrm{N}$ element mainly exists in the form of $-\mathrm{NH}_{2}$. These polar groups may form hydrogen bonds and covalent bonds with the adhesive molecules $[34,35]$ as illustrated in Figure 16, which therefore improves the lap-shear strength of the adhesive interface. In addition, it can be concluded from Figure 11 that the surface of plasma-treated CFRP substrate is more hydrophilic, which provides a better bonding condition between the adhesive and CFRP substrate surface and consequently further improves the lap-shear strength of the adhesive-bonded joints. Figure 17 summarizes the above discussion in order to better understand the effect of APPT on the CFRP substrate surface.

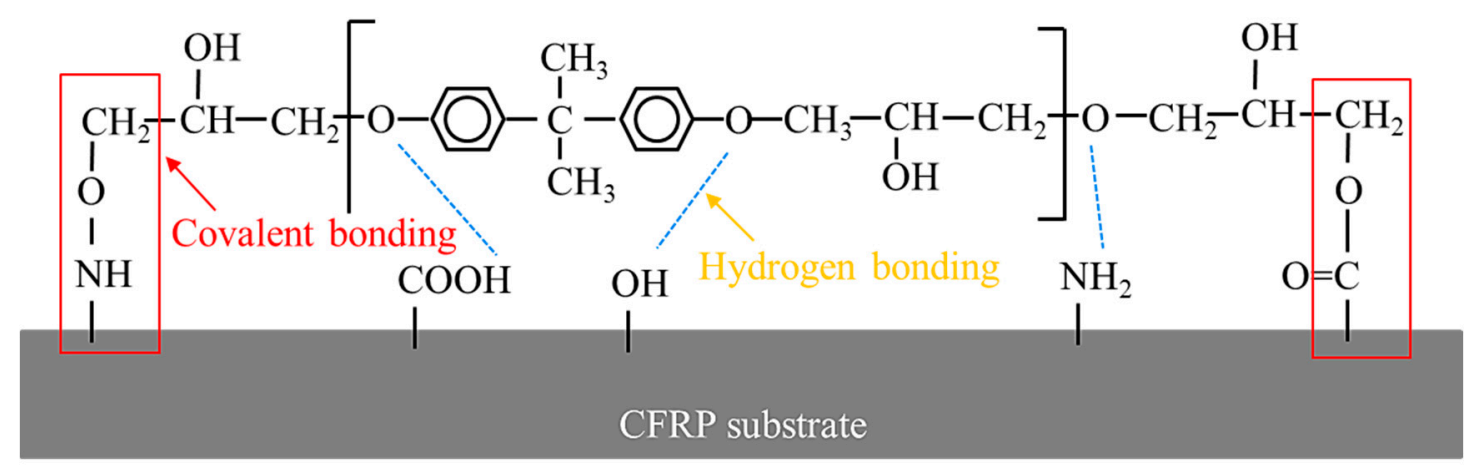

Figure 16. Activated groups and adhesive molecules forming bonding on the CFRP substrate surface.
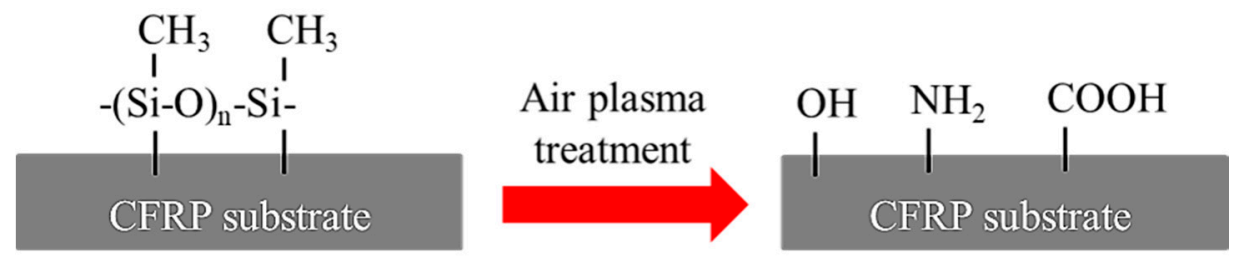

Figure 17. Schematic diagram of atmospheric pressure plasma treatment for the modification of CFRP surface.

It can be seen from the changes in the contents of $\mathrm{Si},-\mathrm{CH}_{3},-\mathrm{OH},-\mathrm{COOH}$, and $-\mathrm{NH}_{2}$ after APPT, the cleaning effect of surface release agent and surface activation with increasing polar groups would be improved as $v$ and/or $h$ decreased, which consequently contributed to the increase in lap-shear strength of plasma-treated CFRP joints. However, the lap-shear strength of plasma-treated CFRP joints would decrease when a slow $v$ (e.g., $v<5 \mathrm{~mm} / \mathrm{s}$ ) and/or a small $h$ (e.g., $h<18 \mathrm{~mm}$ ) were applied, which was mainly attributed to the thermal damage occurring on CFRP substrates caused by high temperatures. The thermal damage decreases the mechanical properties of CFRP substrate and results in the failure of CFRP substrate during lap-shear tensile testing, which consequently decreases the lap-shear strength of plasma-treated CFRP joints. The DSC testing result suggests that the epoxy resin began to react chemically when the temperature was over $175.3^{\circ} \mathrm{C}$ and TGA result shows that the epoxy resin was almost completely pyrolysed when the temperature reached about $340{ }^{\circ} \mathrm{C}$. Therefore, there were many pores on the surface of the epoxy resin (e.g., in Figure 8d) when the surface temperature of the CFRP substrate was $208^{\circ} \mathrm{C}$ during APPT; while the CFRP substrate surfaces in Figure 8e did not exhibit obvious pores after APPT where the surface temperature was only $174{ }^{\circ} \mathrm{C}$. As the temperature rose further to $482{ }^{\circ} \mathrm{C}$, the epoxy resin was removed and carbon fibers were exposed.

Therefore, to effectively remove surface contaminates, generate sufficient polar groups, and simultaneously avoid introducing thermal damage to the CFRP substrates, the surface temperature of CFRP substrate should be controlled between $138^{\circ} \mathrm{C}$ and $175.3^{\circ} \mathrm{C}$ during APPT. The relationship 
among the surface temperature of CFRP substrate, $v$ and $h$ has been established based on the empirical model, i.e., Equation (1), which can be applied to the guidance of selecting the parameters $v$ and $h$ in the APPT of CFRP substrates.

\section{Conclusions}

In this study, the effect of atmospheric pressure plasma treatment on the static lap-shear strength of the adhesive-bonded CFRP joints was investigated. The mechanism was discussed based on various experimental evidences, and conclusions can be drawn as follows:

1. Atmospheric pressure plasma treatment increases the lap-shear strength of adhesive-bonded CFRP joints by $267 \%$ (from $8.6 \mathrm{MPa}$ to $31.6 \mathrm{MPa}$ ) when a nozzle speed of $5 \mathrm{~mm} / \mathrm{s}$ and a nozzle distance of $18 \mathrm{~mm}$ were applied, which is attributed to both the removal of surface contaminants (e.g., release agent) and the generation of polar groups (e.g., $-\mathrm{OH},-\mathrm{COOH}$, and $-\mathrm{NH}_{2}$ ). Further study is required to quantify the contribution of each aspect to the improved CFRP joint strength.

2. During the plasma treatment process, the surface temperature of CFRP substrate should be controlled between $138^{\circ} \mathrm{C}$ and $175.3^{\circ} \mathrm{C}$. When the temperature is below $138^{\circ} \mathrm{C}$, favorable surface modification by plasma treatment is not obvious. A temperature higher than $175.3^{\circ} \mathrm{C}$ causes the thermal damage of CFRP substrate.

3. The surface temperature of CFRP substrate during APPT is expressed as a function of nozzle distance and nozzle speed to guide the selection of plasma treatment process parameters.

Author Contributions: C.S., J.M. and J.L. conceived and designed the experiments; C.S. and H.W. performed the experiments; J.M. analyzed the data; J.L. contributed reagents/materials/analysis tools; C.S. wrote the paper.

Funding: This research was funded by the National Natural Science Foundation of China [51575397].

Acknowledgments: Authors would like to thank Shuang Wang, Qingbao Yang for their valuable support during the experiments. Chengcheng Sun, Junying Min, Jianping Lin and Hailang Wan would like to greatly thank the financial support from National Natural Science Foundation of China (No. 51575397). On behalf of all authors, the corresponding author states that there is no conflict of interest.

Conflicts of Interest: The authors declare no conflict of interest.

\section{References}

1. Ali, A.L.; Philipp, H.; Michael, S. Eco-efficiency assessment of manufacturing carbon fiber reinforced polymers (CFRP) in aerospace industry. Aerosp. Sci. Technol. 2018.

2. Subhani, M.; Globa, A.; Al-Ameri, R.; Moloney, J. Flexural strengthening of LVL beam using CFRP. Constr. Build. Mater. 2017, 150, 480-489. [CrossRef]

3. Khalil, Y.F. Eco-efficient lightweight carbon-fiber reinforced polymer for environmentally greener commercial aviation industry. Sustain. Prod. Consum. 2017, 12, 16-26. [CrossRef]

4. Adams, R.D. Adhesive Bonding: Science, Technology and Applications; CRC Press: Boca Raton, FL, USA; Woodhead Pub: Sawston, UK, 2005.

5. Wu, Y.; Lin, J.; Carlson, B.E.; Lu, P.; Balogh, M.P.; Irish, N.P.; Mei, Y. Effect of laser ablation surface treatment on performance of adhesive-bonded aluminum alloys. Surf. Coat. Technol. 2016, 304, 340-347. [CrossRef]

6. Davis, G.D. Contamination of surfaces: Origin, detection and effect on adhesion. Surf. Interface Anal. 1993, 20,368-372. [CrossRef]

7. Wingfield, J.R.J. Treatment of composite surfaces for adhesive bonding. Int. J. Adhes. Adhes. 1993, 13, 151-156. [CrossRef]

8. Jang, J.; Yang, H. The effect of surface treatment on the performance improvement of carbon fiber/polybenzoxazine composites. J. Mater. Sci. 2000, 35, 2297-2303. [CrossRef]

9. Semitekolos, D.; Kainourgios, P.; Jones, C.; Rana, A.; Koumoulos, E.P.; Charitidis, C.A. Advanced carbon fibre composites via poly methacrylic acid surface treatment; surface analysis and mechanical properties investigation. Compos. Part B Eng. 2018, 155, 237-243. [CrossRef]

10. Fischer, F.; Kreling, S.; Jäschke, P.; Frauenhofer, M.; Kracht, D.; Dilger, K. Laser surface pre-treatment of CFRP for adhesive bonding in consideration of the absorption behavior. J. Adhes. 2012, 88, 350-363. [CrossRef] 
11. Rossi, F.; Kylian, O.; Rauscher, H.; Hasiwa, M.; Gilliland, D. Low pressure plasma discharges for the sterilization and decontamination of surfaces. New J. Phys. 2009, 11, 115017. [CrossRef]

12. Dhayal, M.; Alexander, M.R.; Bradley, J.W. The surface chemistry resulting from low-pressure plasma treatment of polystyrene: The effect of residual vessel bound oxygen. Appl. Surf. Sci. 2006, 252, 7957-7963. [CrossRef]

13. Kusano, Y. Atmospheric pressure plasma processing for polymer adhesion: A review. J. Adhes. 2014, 90, 755-777. [CrossRef]

14. Kim, J.; Lee, D.G. Characteristics of plasma surface treated composite adhesive joints at high environmental temperature. Compos. Struct. 2002, 57, 37-46. [CrossRef]

15. Kim, J.; Lee, D.G. Adhesion characteristics of plasma surface treated carbon/epoxy composite. J. Adhes. Sci. Technol. 2003, 17, 1017-1037. [CrossRef]

16. Williams, T.S.; Yu, H.; Yeh, P.C.; Yang, J.M.; Hicks, R.F. Atmospheric pressure plasma effects on the adhesive bonding properties of stainless steel and epoxy composites. J. Compos. Mater. 2014, 48, 219-233. [CrossRef]

17. Zaldivar, R.J.; Nokes, J.; Steckel, G.L.; Kim, H.I.; Morgan, B.A. The Effect of atmospheric plasma treatment on the chemistry, morphology and resultant bonding behavior of a pan-based carbon fiber-reinforced epoxy composite. J. Compos. Mater. 2010, 44, 137-156. [CrossRef]

18. Schäfer, J.; Hofmann, T.; Holtmannspötter, J.; Frauenhofer, M.; von Czarnecki, J.; Gudladt, H.-J. Atmospheric-pressure plasma treatment of polyamide 6 composites for bonding with polyurethane. J. Adhes. Sci. Technol. 2015, 29, 13. [CrossRef]

19. Comyn, J.; Mascia, L.; Xiao, G.; Parker, B.M. Plasma-treatment of polyetheretherketone (PEEK) for adhesive bonding. Int. J. Adhes. Adhes. 1996, 16, 97-104. [CrossRef]

20. Wang, S.; Min, J.; Lin, J.; Sun, C.; Yang, S. Effect of atmospheric pressure plasma treatment on the lap-shear strength of adhesive-bonded sheet molding compound joints. Automot. Innov. 2018, 1, 237-246. [CrossRef]

21. Standard Test Method for Apparent Shear Strength of Single-Lap-Joint Adhesively Bonded Metal Specimens by Tension Loading (Metal-to-Metal); ASTM D1002-2001; American Society for Testing Materials: West Conshohocken, PA, USA, 2001.

22. Wang, X.; Lin, J.; Min, J.; et al. Effect of atmospheric pressure plasma treatment on strength of adhesive-bonded aluminum AA5052. J. Adhes. 2018, 94, 1-22. [CrossRef]

23. Weber, R.; Hafner, M.; Michalowski, A.; Mucha, P.; Graf, T. Analysis of thermal damage in laser processing of CFRP. In Proceedings of the International Congress on Applications of Lasers and Electro-Optics, Orlando, FL, USA, 23-27 October 2011.

24. Sun, C.; Min, J.; Lin, J.; Wan, H.; Yang, S.; Wang, S. The effect of laser ablation treatment on the chemistry, morphology and bonding strength of CFRP joints. Int. J. Adhes. Adhes. 2018, 84, 325-334. [CrossRef]

25. Hartwig, A.; Vitr, G.; Dieckhoff, S.; Hennemann, O.-D. Surface treatment of an epoxy resin by $\mathrm{CO}_{2}$ laser irradiation. Angew. Makromol. Chem. Macromol. Chem. Phys. 1996, 238, 177-189. [CrossRef]

26. Xingwen, S.; Shenghua, M. Study on silicone oil release agent of PU elastomer mould. Polyurethane Ind. 2005, $5762,65-71$.

27. Bónová, L.; Zahoranová, A.; Kováčik, D.; Zahoran, M.; Mičušík, M.; Černák, M. Atmospheric pressure plasma treatment of flat aluminum surface. Appl. Surf. Sci. 2015, 331, 79-86. [CrossRef]

28. Rhee, K.Y.; Choi, N.S.; Park, S.J. Effect of plasma treatment of aluminum on the bonding characteristics of aluminum-CFRP composite joints. J. Adhes. Sci. Technol. 2002, 16, 14. [CrossRef]

29. Rojewska, M.; Bartkowiak, A.; Strzemiecka, B.; Jamrozik, A.; Voelkel, A.; Prochaska, K. Surface properties and surface free energy of cellulosic etc. mucoadhesive polymers. Carbohydr. Polym. 2017, 171, 152-162. [CrossRef] [PubMed]

30. Owens, D.K.; Wendt, R.C. Estimation of the surface free energy of polymers. J. Appl. Polym. Sci. 1969, 13, 1741-1747. [CrossRef]

31. Zheng, R.; Lin, J.; Wang, P.C.; Zhu, C.; Wu, Y. Effect of adhesive characteristics on static strength of adhesive-bonded aluminum alloys. Int. J. Adhes. Adhes. 2015, 57, 85-94. [CrossRef]

32. Boutar, Y.; Naïmi, S.; Mezlini, S.; Sik Ali, M.B. Effect of surface treatment on the shear strength of aluminium adhesive single-lap joints for automotive applications. Int. J. Adhes. Adhes. 2016, 67, 38-43. [CrossRef]

33. Zimmermann, S.; Specht, U.; Spieß, L.; Romanus, H.; Krischok, S.; Himmerlich, M.; Ihde, J. Improved adhesion at titanium surfaces via laser-induced surface oxidation and roughening. Mater. Sci. Eng. A 2012, 558, 755-760. [CrossRef] 
34. Fedoseev, M.; Gurina, M.; Sdobnov, V.; Kondyurin, A. Study of the reaction of epoxides with carboxylic acids by IR and Raman spectrometry. J. Raman Spectrosc. 1996, 27, 413-418. [CrossRef]

35. Blank, W.J.; He, Z.A.; Picci, M. Catalysis of the epoxy-carboxyl reaction. J. Coat. Technol. 2002, 74, $33-41$. [CrossRef]

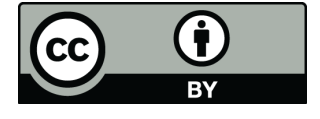

(C) 2019 by the authors. Licensee MDPI, Basel, Switzerland. This article is an open access article distributed under the terms and conditions of the Creative Commons Attribution (CC BY) license (http:/ / creativecommons.org/licenses/by/4.0/). 